\title{
Análise química da água de entrada no sistema agroindustrial de curtume em Maringá
}

Chemical analysis of the entry water in the agricultural system of curtume in Maringá

\author{
Adriano Willian da Silva', Frederico Fonseca da Silva"
}

\begin{abstract}
RESUMO
O controle físico, químico e biológico da qualidade da água é um fator fundamental para a sobrevivência e saúde humana. Sem água, não há vida no planeta Terra que, por sua vez, também é conhecido como Planeta Água. Neste trabalho, investiga-se a partir de parâmetros químicos, tais como alcalinidade total, cloretos, bicarbonato, fosfatos, nitratos, hidróxidos, nitritos, dentre outros, a qualidade da água em cinco períodos, compreendidos entre os anos de 2014 a 2017 de um sistema agroindustrial de curtume, localizado em Maringá (Paraná). Os resultados encontrados e analisados sob os auspícios da legislação ambiental em vigor demonstram que a qualidade da água de entrada encontrada no sistema está de acordo com as normativas ambientais vigentes, indicando um controle efetivo do sistema agroindustrial implementado e uma qualidade da água que não a torna prejudicial ao meio ambiente.
\end{abstract}

Palavras chave: Monitoramento; Parâmetros; Qualidade da água

\section{ABSTRACT}

Physical, Chemical and Biological control of water quality is a key factor for human survival and health. Without water, there is no life on planet Earth which, in turn, is also known as Planet Water. In this article, it is investigated from chemical parameters, such as total alkalinity, chlorides, bicarbonate, phosphates, nitrates, hydroxides, nitrites, among others, water quality in five periods, comprised between 2014 and 2017 of an agro-industrial system of tannery, located in the city of Maringa (Brazil). The results found and analyzed under the auspices of the current environmental legislation demonstrate that the incoming water quality found in the system is in accordance with current environmental regulations, indicating an effective control of the implemented agro-industrial system and a water quality that does not make it harmful to the environment.

Keywords: Monitoring; Parameters; Water quality

\section{I.INTRODUÇÃO}

O presente estudo é fruto do Projeto de Pesquisa Consideraçóes ambientais a serem desenvolvidas no Curtume Central, na cidade de Maringá (PR) sob a responsabilidade do primeiro autor onde, uma das atividades apresentada, consistiuem entender a situação atual do processo estabelecendo como estágio inicial do projeto, como forma de propor soluçóes ambientais e viáveis do empreendimento agroindustrial.

Dessa forma, todo o processo de análise de monitoramento do sistema ambiental de águas residuárias agroindustriais, perpassou, obrigatoriamente, pela qualidade da água de entrada nesse sistema, como forma de se entender as suas variaçóes e o todo desse processo.

Outrossim, ao interpretá-las em separado (água de entrada das águas residuárias), sem jamais desvencilhar-se uma da outra, entende-se que toda e qualquer variação de algum dos parâmetros avaliados, seja no âmbito espacial ou temporal, deve ser interpretado objetivando o controle máximo possível, com as suas possíveis análises 
para cada um dos casos e, em especial, tendo um referencial balizador quanto ao modelo adotado.

Para tanto, considerando que o presente monitoramento e estudo localiza-se na área de influencia da cidade de Maringá, na região noroeste do Paraná, se utilizou o IN-001/06, da SUDERHSA (Superintendência de Desenvolvimento de Recursos Hídricos e Saneamento Ambiental), vinculado ao Instituto das Águas do Paraná, como balizador da legislação estadual; e, as Resoluçôes 357/05 e 430/11, ambas do CONAMA (Conselho Nacional de Meio Ambiente), como referencial de legislação Federal.

O uso de águas subterrâneas para consumo humano e atividades agroindustriais no Paraná tem se intensificado nos últimos anos devido, principalmente, à escassez da oferta de águas superficiais com boa qualidade e devido ao fácil acesso aos aquíferos que ocorrem na regiáo (ROSA FILHO et al., 2010).

O Aquífero Serra Geral, que toma praticamente todo o Terceiro Planalto Paranaense, é responsável por complementar o abastecimento público de água no município de Maringá e, como observado no banco de dados do Âguas Paraná, tem fins comerciais, industriais e também, até o período estudado, para irrigação de pequenas áreas agrícolas que estão dentro do perímetro urbano da cidade. Este apresenta uma série de fraturas, o que aumenta sua capacidade de armazenamento de água e substâncias dissolvidas. A água confinada apresenta-se bicarbonatada cálcica e, muito comumente, cálcica-magnesiana, devido a composição da rocha e também do tempo de confinamento desta água neste reservatório natural (ROSA FILHO, 2011).

No Brasil, quando se trata de águas subterrâneas, há duas principais regulamentaçóes que estabelecem diretrizes sobre a qualidade deste recurso, a Resolução CONAMA no 396 de 2008 (BRASIL, 2008) e a Portaria do Ministério da Saúde no 2.914 de 2011 (BRASIL, 2011). Enquanto a primeira dispóe sobre a classificação e enquadramento das águas subterrâneas, a outra abrange procedimentos de controle e de vigilância da qualidade da água para consumo humano e seu padrão de potabilidade. Ambos estabelecem limites para certos parâmetros presentes na água.

Os problemas de degradação da qualidade das águas subterrâneas são mais difíceis de serem superados. Uma vez queheterogeneidades são inerentes aos sistemas de subsuperfície, as zonas de águas subterrâneas degradadas são muito difíceis de detectar (FREEZE e CHERRY, 1979).

Dessa forma, quando da análise e interpretação dos parâmetros no campo dos Resultados e Discussão, a Tabela 1 apresenta a qualidade dos parâmetros químicos da saída da água do poço tubular.

\section{METODOLOGIA}

A metodologia utilizada consistiu em adotar a técnica proposta no Manual Técnicos para coleta de amostras de água, publicado pelo Ministério Público de Santa Catarina onde, para coleta de águas de poços ou cisternas, objetivando os testes químicos: Usou-se balde de metal onde o mesmo foi muito bem lavado internamente e externamente, em seguida o mesmo foi limpo com álcool; Submergiu-se o balde na água; Depois do balde cheio, transferiu-se a amostra para o frasco estéril, enchendo com a amostra até $3 / 4$ de sua capacidade e, em seguida, fechou-se bem o frasco.

Após realizar a coleta, identificaram-se os frascos contendo as amostras e preencheu-se a Requisição de Ensaio, onde os mesmos foram armazenados de acordo com o recomendado para as diferentes análises e parâmetros a serem avaliados.

Depois do processo de preservação, todos os frascos foram acondicionadossob refrigeração em uma caixa térmica com gelo comum filtrado, em quantidade suficiente para preencher os espaços vazios da caixa.

O tempo entre a coleta e o recebimento da amostra pelo setor de recepção, foi inferior a 24 horas, tanto para as amostras destinadas.

Para as referências normativas, utilizou-se o Standard Methods for the Examination of Water and Wastewater, 22 $2^{\text {th }}$ Edition (APHA / AWWA).

\section{RESULTADOS E DISCUSSÃO}

A Tabela 1 apresenta a qualidade dos parâmetros químicos da água do poço tubular. 
Tabela 1 - Qualidade dos parâmetros químicos da saída da água do poço tubular (água de entrada no sistema a ser analisada no contexto ambiental)

\begin{tabular}{|c|c|c|c|c|c|c|c|}
\hline \multirow[b]{2}{*}{ Parâmetros } & \multirow[b]{2}{*}{ Unidades } & \multirow{2}{*}{$\begin{array}{l}\text { IN-001/06 } \\
\text { (Suderhsa) }\end{array}$} & \multicolumn{5}{|c|}{ Resultados analíticos } \\
\hline & & & $\begin{array}{c}09 / 2014 \\
\text { P1 } \\
\end{array}$ & $\begin{array}{c}09 / 2014 \\
\text { P2 } \\
\end{array}$ & $\begin{array}{c}03 / 2016 \\
\text { P1 } \\
\end{array}$ & $\begin{array}{c}05 / 2016 \\
\text { P1 } \\
\end{array}$ & $\begin{array}{c}\text { 08/2017 } \\
\text { P1 } \\
\end{array}$ \\
\hline $\begin{array}{l}\text { Alcalinidade em } \\
\text { Hidróxidos }\end{array}$ & $\mathrm{mg} \cdot \mathrm{L}^{-1}$ & - & $<1,0$ & $<1,0$ & NA & NA & NA \\
\hline Alcalinidade Total & $\mathrm{mg} \cdot \mathrm{L}^{-1}$ & - & 109,6 & 117,1 & 77,5 & 101,0 & 105,3 \\
\hline Ânions & meq L-1 & - & NA & NA & 2,21 & 2,56 & 2,22 \\
\hline Balanço Iônico & mg.L.-1 & - & 5,19 & 8,42 & NA & NA & NA \\
\hline Bicarbonato & mg.L.-1 & - & 109,63 & 117,05 & 77,46 & 101,0 & 105,3 \\
\hline Carbonato & mg. $\mathrm{L}^{-1}$ & - & $<1,0$ & $<1,0$ & $<3,0$ & $<3,0$ & $<3,0$ \\
\hline Cálcio & mg. $\mathrm{L}^{-1}$ & - & 21,82 & 42,42 & 24,87 & NA & 32,11 \\
\hline Cátions & meq $\mathrm{L}^{-1}$ & - & NA & NA & 2,42 & 3,46 & 3,50 \\
\hline Cloretos & meq L-1 & - & 37,93 & 32,34 & NA & 26,06 & $\mathrm{NA}$ \\
\hline Cloretos & mg.L-1 & Até 250,0 & NA & NA & 16,5 & NA & 11,5 \\
\hline DBI & $\%$ & - & 13,67 & 30,21 & 4,52 & 14,88 & 22,31 \\
\hline $\begin{array}{l}\text { Dióxido de Carbono } \\
\text { Livre }\end{array}$ & mg.L.-1 & - & 70,95 & 57,46 & 5,37 & 21,15 & 11,84 \\
\hline $\mathrm{DQO}$ & mg.L.-1 & - & $<3,0$ & $<3,0$ & $<15,0$ & 17,0 & $<15,0$ \\
\hline Ferro & $\mathrm{mg} . \mathrm{L}^{-1}$ & até 0,30 & $<0,01$ & $<0,01$ & NA & $<0,01$ & 0,10 \\
\hline Fosfato Total & $\mathrm{mg} \cdot \mathrm{L}^{-1}$ & & $<0,05$ & $<0,05$ & NA & $<0,15$ & $<0,15$ \\
\hline Fluoretos & mg.L.- & Até 1,5 & $<0,10$ & 0,15 & $<0,10$ & 0,10 & $<0,10$ \\
\hline Hidróxidos & mg.L.-1 & - & NA & $\mathrm{NA}$ & $<3,0$ & $<3,0$ & $<3,0$ \\
\hline Magnésio & mg.L.-1 & - & 5,63 & 12,25 & NA & 9,74 & 15,82 \\
\hline Manganês & mg.L. - $^{-1}$ & até 0,100 & $<0,005$ & $<0,005$ & NA & $<0,005$ & $<0,005$ \\
\hline $\mathrm{N}$ nitrato & mg.L. ${ }^{-1}$ & Até 10,0 & 5,1 & 6,2 & 6,6 & 2,3 & 2,4 \\
\hline $\mathrm{N}$ nitrito & mg.L. ${ }^{-1}$ & Até 1,0 & $<0,01$ & $<0,01$ & $<0,01$ & 0,02 & $<0,01$ \\
\hline Potássio & mg.L. ${ }^{-1}$ & - & 1,8 & $<1,0$ & NA & 1,2 & $<1,0$ \\
\hline Sílica dissolvida & mg.L.-1 & - & 47,5 & 26,0 & 50,7 & 50,3 & 16,7 \\
\hline Sódio & mg.L. ${ }^{-1}$ & até 200 & 14,8 & 54,2 & NA & 12,0 & 13,5 \\
\hline Sulfato & mg.L.-1 & Até 250 & $<2,0$ & $<2,0$ & $<2,0$ & $<2,0$ & $<2$ \\
\hline
\end{tabular}

Legenda:meq $\mathrm{L}^{-1}$ - Microequivalente grama por Litro; mg.L-1 - Miligrama por Litro; \% - Percentagem; NA - Não analisado; P1 - Poço 1; P2 - Poço 2

\section{I AlCalinidade em HidRóxidos}

Entre as impurezas encontradas na águas, existem aquelas que são capazes de reagir com ácidos, podendo neutralizar certa quantidade desses reagentes. Essas impurezas conferem às águas a característica de alcalinidade. Por definição, a alcalinidade representa a capacidade que um sistema aquoso tem de tamponar ácidos a ele adicionados até um determinado $\mathrm{pH}$. E, corresponde à presença de sais de ácidos fracos, bases fortes e bases fracas. Esta capacidade depende de alguns compostos, principalmente bicarbonatos, carbonatos, hidróxidos, fosfatos, silicatos, sais de ácidos orgânicos fracos, e amoníaco. A alcalinidade é determinada através da titulação e pode ser expressa de algumas maneiras quanto a parcialidade ou totalidade de hidroxila.

Alcalinidade (Alcalinidade Hidróxida $\mathrm{OH}^{-}$) ouAlcalinidade de hidróxidos ou ainda causticidade é uma componente da alcalinidade total devida, exclusivamente, à presença de íons $\mathrm{OH}^{-}$. Náo se deve confundir Alcalinidade com a medida de íons $\mathrm{H}^{+}$ou $\mathrm{OH}^{-}$livres. Estes são realizados através da determinação de $\mathrm{pH}$. A Alcalinidade não é normalmente encontrada em águas naturais, podendo ser adicionada sob a forma de produtos cáusticos. Alcalinidade total é a soma da alcalinidade produzida por todos estes íons presentes numa água. Águas 
que percolam rochas calcárias (calcita $=\mathrm{CaCO}_{3}$ ) geralmente possuem alcalinidade elevada. Granitos e gnaisses, rochas comuns em muitos Estados brasileiros, possuem poucos minerais que contribuem para a alcalinidade das água subterrâneas.

Essa é a razão pela qual, quando analisada a água dos poços a sua concentração seja muito baixa, conforme extrato da Tabela 1, indicado para esse parâmetro em análise.

Tabela 2 - Resultados obtidos para Alcalinidade em Hidróxidos

\begin{tabular}{|c|c|c|c|c|c|c|c|}
\hline \multirow[b]{2}{*}{ Parâmetros } & \multirow[b]{2}{*}{ Unidades } & \multirow{2}{*}{$\begin{array}{c}\text { IN-001/06 } \\
\text { (SUDERHSA) }\end{array}$} & \multicolumn{5}{|c|}{ Resultados analíticos } \\
\hline & & & $\begin{array}{c}\text { 09/2014 } \\
\text { P1 }\end{array}$ & $\begin{array}{c}\text { 09/2014 } \\
\text { P2 }\end{array}$ & $\begin{array}{c}03 / 2016 \\
\text { P1 }\end{array}$ & $\begin{array}{c}05 / 2016 \\
\text { P1 }\end{array}$ & $\begin{array}{c}\text { 08/2017 } \\
\text { P1 }\end{array}$ \\
\hline Alcalinidade em Hidróxidos & $\mathrm{mg} \cdot \mathrm{L}^{-1}$ & - & $<1,0$ & $<1,0$ & NA & NA & NA \\
\hline
\end{tabular}

\subsection{Alcalinidade Total}

A alcalinidade da água é umamedida de sua capacidade em reagir com ácidos fortes para atingir determinado valor de $\mathrm{pH}$. A alcalinidade da água natural é, tipicamente, uma combinação de $\mathrm{HCO}_{3}-\mathrm{CO}_{3}{ }^{2-} \mathrm{e} \mathrm{OH}^{-}$. É determinada por titulação com ácido forte em presença de alaranjado de metila. Na água potável, a alcalinidade contribui, também, para o sabor da água.

A alcalinidade total de uma água é expressa em mg. $\mathrm{L}^{-1}$ de $\mathrm{CaCO}_{3}$. Segundo a Resolução CNNPA no 12 (ANVISA, 1978), as águas para consumo alimentar de abastecimento público devem satisfazer a seguinte característica em termos de alcalinidade: de hidróxidos - zero; de carbonatos - até $120 \mathrm{mg} \cdot \mathrm{L}^{-1} \mathrm{em} \mathrm{CaCO}_{3}$; e de bicarbonatos - até $250 \mathrm{mg} \cdot \mathrm{L}^{-1} \mathrm{em} \mathrm{CaCO}$.

Em águas subterrâneas a alcalinidade é devida principalmente aos carbonatos e bicarbonatos e, secundariamente, aos íons hidróxidos, silicatos, boratos, fosfatos e amônia.

Tabela 3 - Resultados obtidos para Alcalinidade Total

\begin{tabular}{c|c|c|c|c|c|c|c}
\hline \multirow{2}{*}{ Parâmetros } & \multirow{2}{*}{ Unidades } & \multirow{2}{*}{$\begin{array}{c}\text { IN-001/06 } \\
\text { (SUDERHSA) }\end{array}$} & \multicolumn{6}{|c}{ Resultados analíticos } \\
\cline { 4 - 8 } & & $\mathbf{0 9 / 2 0 1 4}$ & $\mathbf{0 9 / 2 0 1 4}$ & $\mathbf{0 3 / 2 0 1 6}$ & $\mathbf{0 5 / 2 0 1 6}$ & $\mathbf{0 8 / 2 0 1 7}$ \\
& & - & 109,6 & 117,1 & 77,5 & 101,0 & 105,3 \\
\hline Alcalinidade Total & $\mathrm{mg} . \mathrm{L}^{-1}$ & - & $\mathbf{P 2}$ & $\mathbf{P 1}$ & P1 & P1 \\
\hline
\end{tabular}

\section{3 ÂNIONS E CÁtIONS}

Em estudos de hidrogeologia é comum a determinação de ânions em águas por cromatografia de íons (CI). Muitas das conclusóes obtidas nos diversos estudos são baseadas nos resultados analíticos gerados através das análises químicas das amostras, por isso, a importância da credibilidade nos resultados. Na cromatografia de íons, como em qualquer outra técnica analítica, é necessário fazer constantes verificaçóes da qualidade dos dados gerados e sua manutenção ao longo do tempo (VENDEMIATTO et al., s/d).

Os cromatógrafos de íons são instrumentos onde são feitas as separaçôes cromatográficas das espécies desejadas seguida da sua detecção. No caso da determinação de ânions (fluoreto, cloreto, nitrito, sulfato, brometo, nitrato e fosfato, como serão interpretados em separado, a seguir) em águas, o detector usado é o de condutividade.

Observa-se que nas análises temporais de 2016 e 2017, conforme recorte da Tabela 1, os seus valores são baixos, muito embora não exista restrição de valor máximo permitido(VMP) para ânions pela legislação vigente.

Tabela 4 - Resultados obtidos para Alcalinidade Total

\begin{tabular}{|c|c|c|c|c|c|c|c|}
\hline \multirow[b]{2}{*}{ Parâmetros } & \multirow[b]{2}{*}{ Unidades } & \multirow{2}{*}{$\begin{array}{c}\text { IN-001/06 } \\
\text { (SUDERHSA) }\end{array}$} & \multicolumn{5}{|c|}{ Resultados analíticos } \\
\hline & & & $\begin{array}{c}\text { 09/2014 } \\
\text { P1 }\end{array}$ & $\begin{array}{c}09 / 2014 \\
\text { P2 }\end{array}$ & $\begin{array}{c}\text { 03/2016 } \\
\text { P1 }\end{array}$ & $\begin{array}{c}\text { 05/2016 } \\
\text { P1 }\end{array}$ & $\begin{array}{c}\text { 08/2017 } \\
\text { P1 }\end{array}$ \\
\hline Ânions & $\mathrm{mg} \cdot \mathrm{L}^{-1}$ & - & NA & NA & 2,21 & 2,56 & 2,22 \\
\hline Cátions & $\mathrm{mg} \cdot \mathrm{L}^{-1}$ & - & NA & NA & 2,42 & 3,46 & 3,50 \\
\hline
\end{tabular}




\subsection{BALANÇO IÔNICO}

Trata-se da $\sum$ ânions $\cong \sum$ cátions, conforme apresentado nos parâmetros acima, e que, em condições normais, tendem a se equilibrarem ou apresentarem diferenças não significativas. Em uma análise hidroquímica completa, a concentração total de íons positivos (cátions) deve ser aproximadamente igual à concentração de íons negativos (ânions).

Dessa forma, entende-se como Balanço Iônico como sendo proporções de determinados cátions e ânions expressos em mg. $\mathrm{L}^{-1}$, que devem ser mantidos para que os organismos vivos se desenvolvam de forma saudável.

Dependendo do uso ou fim ao qual se destina, o estudo de algumas relações algumas relações são fundamentais e de particular interesse, tais como: $\mathrm{Na} / \mathrm{K}, \mathrm{K} / \mathrm{Ca}, \mathrm{Ca} / \mathrm{Mg}, \mathrm{Ca} / \mathrm{Na}$ ou ainda a relação $\mathrm{Ca} / \mathrm{Mg} / \mathrm{K}$, dentre outras.

Diante do exposto observa-se para as análises realizadas em 03/2016, 05/2016 e 08/2017, respectivamente, ânions e cátions, para o poço 1 (P1), verifica-se uma leve concentração de cátions maior do que ânions, na ordem de, $0,21,0,90$ e 1,28 mg. $\mathrm{L}^{-1}$.

O cálculo do balanço iônico foi aplicado em cada amostra para verificar os resultados das análises químicas antes que fossem feitas as análises estatísticas. O erro do balanço iônico aceitável compreende ao intervalo entre $\pm 20 \%$, pois foi utilizado para o credenciamento do laboratório. O balanço iônico é definido pela equação 1, onde as concentrações dos cátions e ânions estão em meq L $\mathrm{L}^{-1}$ (SCOPELet al., 2005):

$$
\text { Erro do balanço iônico }(\%)=\text { x } 100 \text { (equação } 1)
$$

O resultado deste cálculo é dado em porcentagem e deve respeitar as variâncias apresentadas no Quadro 1. O DBI em porcentagem é dado a partir da equação 1 .

Tabela 5 - Relação de erro permissível em função da soma de cátions e ânions

\begin{tabular}{l|c}
\hline Soma de ânions $\left(\mathbf{m e q} \mathbf{~ L}^{-1}\right)$ & Diferença aceitável (\%) \\
\hline $0-3.0$ & \pm 0.23 \\
\hline $0-10.0$ & \pm 2 \\
\hline $10.0-800$ & \pm 5 \\
\hline
\end{tabular}

Fonte: Rosa Filho et al., (2010).

\subsection{Determinação do Balanço lônico- DBI}

A percentagem da DBI define o desvio percentual, erro, objetivando o controle de qualidade da análise hidroquímica.

Como caracterização hidroquímica, a análise da composição química das águas subterrâneas e de suas variaçóes, sem alteraçôes causadas por açóes antropogênicas.

Tabela 6 - Relação de erro permissível em função da soma de cátions e ânions

\begin{tabular}{l|c|c|c|c|c|c|c}
\hline \multirow{3}{*}{ Parâmetros } & \multirow{2}{*}{ Unidades } & \multirow{2}{*}{$\begin{array}{c}\text { IN-001/06 } \\
\text { (SUDERHSA) }\end{array}$} & \multicolumn{6}{|c}{ Resultados analíticos } \\
\cline { 4 - 8 } & & & $\mathbf{0 9 / 2 0 1 4}$ & $\mathbf{0 9 / 2 0 1 4}$ & $\mathbf{0 3 / 2 0 1 6}$ & $\mathbf{0 5 / 2 0 1 6}$ & $\mathbf{0 8 / 2 0 1 7}$ \\
& & - & 13,67 & 30,21 & 4,52 & 14,88 & 22,31 \\
\hline DBI & $\%$ & - & P2 & P1 & P1 & P1 \\
\hline
\end{tabular}

O Diagrama de Piper (Figura 1) é frequentemente utilizado para classificação e comparação de distintos grupos de águas quanto aos íons dominantes. O diagrama mostra a classificação das amostras segundo este critério. A representação gráfica pode evidenciar possíveis relaçôes entre íons de uma mesma amostra, ou ressaltar variações temporais ou espaciais existentes. 
Figura 1- Diagrama de Piper

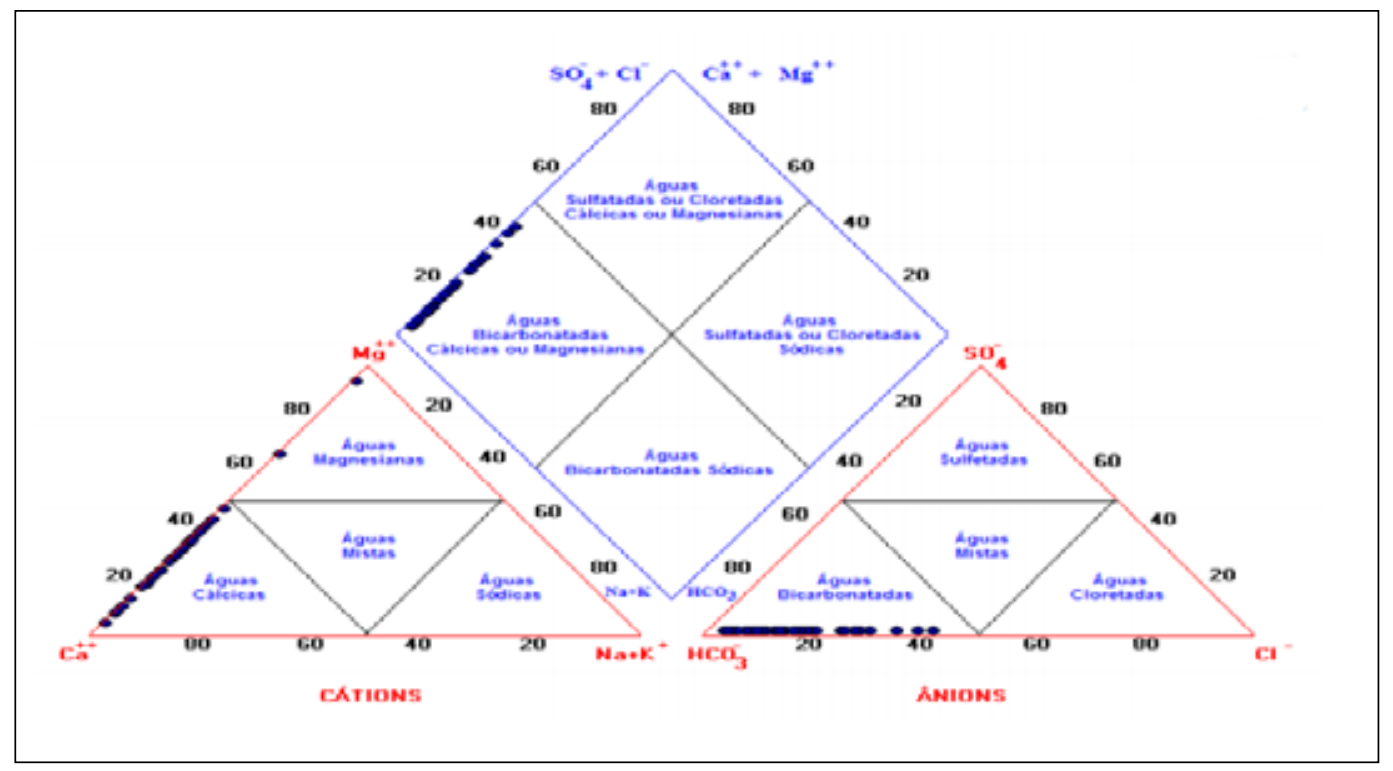

\subsection{Bicarbonato e Carbonato}

A dureza de carbonatos também é conhecida como dureza em carbonatos, dureza carbonatada, alcalinidade/KH (Karbonathärte Hardness), potencial alcalino, capacidade de tamponamento, dureza temporária ou fração instável da dureza total.

A dureza de carbonatos/carbonatada se refere apenas aos carbonatos e bicarbonatos dissolvidos na água, pois existem outros compostos, inclusive alguns fosfatos, silicatos e outros que também possuem o efeito tampão.

São os bicarbonatos que representam a maior parte da alcalinidade na água, pois os mesmos são formados em quantidade consideráveis pela ação do $\mathrm{CO}_{2}$ com materiais básicos presentes no solo. Em outras palavras, esta variável, alcalinidade, caracteriza a capacidade de neutralização de ácidos na água, ou seja, mede as bases na água.

A maioria dos carbonatos é solúvel em água, apenas os carbonatos de metais alcalinos e amônio não se solubilizam em água.

Os valores para esses parâmetros, com base no estrato da Tabela 1, estão condizentes com as águas subterrâneas e sem nenhum VMP pela legislação vigente, refletindo em valores de $\mathrm{pH}$ próximos a neutralidade ao longo das análises e monitoramento, conforme exposto naquele parâmetro.

Tabela 7 - Resultados obtidos para o Bicarbonato e Carbonato

\begin{tabular}{l|c|c|c|c|c|c|c}
\hline \multirow{3}{*}{ Parâmetros } & \multirow{2}{*}{ Unidades } & \multirow{2}{*}{$\begin{array}{c}\text { IN-001/06 } \\
\text { (SUDERHSA) }\end{array}$} & \multicolumn{5}{|c}{ Resultados analíticos } \\
\cline { 4 - 8 } & & & $\mathbf{0 9 / 2 0 1 4}$ & $\mathbf{0 9 / 2 0 1 4}$ & $\mathbf{0 3 / 2 0 1 6}$ & $\mathbf{0 5 / 2 0 1 6}$ & $\mathbf{0 8 / 2 0 1 7}$ \\
& & - & 109,63 & 117,05 & 77,46 & 101,0 & 105,3 \\
\hline Bicarbonato & $\mathrm{mg} \cdot \mathrm{L}^{-1}$ & - & $<1,0$ & $<1,0$ & $<3,0$ & $<3,0$ & $<3,0$ \\
\hline Carbonato & $\mathrm{mg} \cdot \mathrm{L}^{-1}$ & - & & & $\mathbf{P 1}$ & $\mathbf{P 1}$ & P1 \\
\hline
\end{tabular}

\subsection{CÁLCIO}

De acordo com Celligot (1999), o cálcio é encontrado em plagioclásios $\left(\mathrm{CaAl}_{2} \mathrm{Si}_{2} \mathrm{O}_{8}\right)$ e em anfibólios e piroxênios - perfaz $25.700 \mathrm{mg} . \mathrm{Kg}^{-1}$ nas rochas ígneas. Forma depósito de carbonatos, calcita e aragonita $\left(\mathrm{CaCO}_{3}\right)$ e de dolomita $\left(\mathrm{CaCO}_{3} \cdot \mathrm{MgCO}_{3}\right)$, bem como a anidrita $\left(\mathrm{CaSO}_{4}\right)$ e diversos minerais. É o cátion mais comum em águas doces. Seu conteúdo na maioria dos casos é determinado pelo sistema equilíbrio $\mathrm{CaCO}_{3}^{-} \mathrm{CO}_{2}^{-} \mathrm{H}_{2} \mathrm{CO}_{3}^{-}$ $\mathrm{HCO}_{3}^{-} \mathrm{CO}_{3}^{2-}$, conhecido como equilíbrio carbonato de cálcio-dióxido de carbono.

Conforme extrato da Tabela 1 para esse parâmetro, a variação desse elemento nas águas extraídas do poço 1 (P1), apresentam flutuaçóes que variam de 21,82 a 32,11 mg. $\mathrm{L}^{-1}$ e não existe VMP pelas legislaçóes para esse parâmetro. 
Tabela 8 - Resultados obtidos para o Bicarbonato e Carbonato

\begin{tabular}{|c|c|c|c|c|c|c|c|}
\hline \multirow[b]{2}{*}{ Parâmetros } & \multirow[b]{2}{*}{ Unidades } & \multirow{2}{*}{$\begin{array}{c}\text { IN-001/06 } \\
\text { (SUDERHSA) }\end{array}$} & \multicolumn{5}{|c|}{ Resultados analíticos } \\
\hline & & & $\begin{array}{c}\text { 09/2014 } \\
\text { P1 }\end{array}$ & $\begin{array}{c}\text { 09/2014 } \\
\text { P2 }\end{array}$ & $\begin{array}{c}03 / 2016 \\
\text { P1 }\end{array}$ & $\begin{array}{c}\text { 05/2016 } \\
\text { P1 }\end{array}$ & $\begin{array}{c}\text { 08/2017 } \\
\text { P1 }\end{array}$ \\
\hline Cálcio & $\mathrm{mg} \cdot \mathrm{L}^{-1}$ & - & 21,82 & 42,42 & 24,87 & NA & 32,11 \\
\hline
\end{tabular}

\subsection{CloRetos}

De acordo com Celligot (1999), as águas dos oceanos constituem-se na maior fonte de cloreto, visto que o intemperismo das rochas ígneas colabora com poucas quantidades. Entretanto, a presença de cloreto em águas subterrâneas pode ser atribuída à dissolução de depósitos salinos, descargas de efluentes de indústrias químicas, intrusões salinas, etc.

Os íons cloreto são altamente móveis e não são retidos em rochas permeáveis. Em argilitos, cristais de $\mathrm{NaCl}$ ou soluçōes de $\mathrm{Na}-\mathrm{Cl}$ podem ser contidos em poros. Os íons cloreto são presentes em baixas concentraçôes $\left(<10 \mathrm{mg} \cdot \mathrm{L}^{-1}\right)$. Altas concentraçôes podem indicar poluição antrópica.

O cloreto é um dos ânions mais comuns em águas naturais, nos esgotos domésticos e em despejos. Não são prejudiciais à saúde do homem, porém conferem sabor salgado à água. Em altas concentraçóes podem trazer restriçôes ao sabor da água.

O cloro é um elemento não metálico, pertencente ao grupo $7 \mathrm{~A}$, halogênio, juntamente com o iodo, bromo e flúor. O cloro possui sete elétrons na camada de valência; portanto, tende a ganhar um elétron, adquirindo a configuração de um gás nobre e formando o íon cloreto, que é a forma mais comumente encontrada na natureza (LEE, 1999, TABELA PERIODICA ONLINE, 2008).

Pelo extrato da Tabela 1 para esse parâmetro observa-se que os seus valores naturais são baixos, flutuando entre 11,5 a 16,5 mg. $\mathrm{L}^{-1}$ diante do VMP estabelecido pela legislação vigente, que é de $250 \mathrm{mg} . \mathrm{L}^{-1}$.

Tabela 9 - Resultados obtidos para o Cloreto

\begin{tabular}{l|c|c|c|c|c|c|c}
\hline \multirow{2}{*}{ Parâmetros } & \multirow{2}{*}{ Unidades } & \multirow{2}{*}{$\begin{array}{c}\text { IN-001/06 } \\
\text { (SUDERHSA) }\end{array}$} & \multicolumn{6}{|c}{ Resultados analíticos } \\
\cline { 5 - 8 } & & & P1 & P2 & P1 & P1 & P1 \\
\hline Cloretos & mg.L & Até 250,0 & NA & NA & 16,5 & NA & 11,5 \\
\hline
\end{tabular}

\subsection{Dióxido de Carbono LiVRe}

De acordo com Celligot (1999), o sistema $\mathrm{CO}_{2}+\mathrm{H}_{2} \mathrm{O}<\mathrm{H}_{2} \mathrm{CO}_{3}<\mathrm{HCO}_{3}+\mathrm{H}<\mathrm{CO}_{3}^{2-}+\mathrm{H}^{+}$é muito importante na água, controlando a formação de várias espécies de carbonato que se originam de rochas carbonáticas e dióxido de carbono livre.

$\mathrm{CO}_{2}$ total é dividido em $\mathrm{CO}_{2}$ livre $\rightarrow$ dióxido de carbono dissolvido e $\mathrm{H}_{2} \mathrm{CO}_{3}$ não dissociado e $\mathrm{CO}_{2}$ limite $\rightarrow$ Hidrogênio carbonato e íons carbonato, sendo que suas origens principais estão no $\mathrm{CO}_{2}$ atmosférico ou no solo.

Os valores expressos pelo extrato da Tabela 1 para esse parâmetro são apresentados a seguir, mas não existindo VMP para esse parâmetro pela legislação vigente.

Tabela 10-. Resultados obtidos para o Dióxido de Carbono Livre

\begin{tabular}{c|c|c|c|c|c|c|c}
\hline \multirow{2}{*}{ Parâmetros } & \multirow{3}{*}{ Unidades } & \multirow{2}{*}{$\begin{array}{c}\text { IN-001/06 } \\
\text { (SUDERHSA) }\end{array}$} & \multicolumn{6}{|c}{ Resultados analíticos } \\
\cline { 4 - 8 } & & & $\mathbf{0 9 / 2 0 1 4}$ & $\mathbf{0 9 / 2 0 1 4}$ & $\mathbf{0 3 / 2 0 1 6}$ & $\mathbf{0 5 / 2 0 1 6}$ & $\mathbf{0 8 / 2 0 1 7}$ \\
& & & $\mathbf{P 1}$ & $\mathbf{P 2}$ & $\mathbf{P 1}$ & $\mathbf{P 1}$ & P1 \\
\hline Dióxido de Carbono Livre & $\mathrm{mg} \cdot \mathrm{L}^{-1}$ & - & 70,95 & 57,46 & 5,37 & 21,15 & 11,84 \\
\hline
\end{tabular}




\section{I D DEMANDA QuímiCA DE OXIGÊNIO- DQO}

A análise dos valores de DQO em efluentes, em águas de superfície e águas subterrâneas é uma das mais expressivas para determinação do grau de poluição da água, esta análise reflete a quantidade total de componentes oxidáveis, seja carbono ou hidrogênio de hidrocarbonetos, nitrogênio (de proteínas, por exemplo), ou enxofre e fósforo de detergentes. Em outras palavras, quanto de oxigênio é necessário para oxidar toda a matéria orgânica existente no meio através de processos e reações químicas.

A DQO se baseia no fato de alguns compostos orgânicos, são oxidados por agentes químicos oxidantes considerados fortes, como por exemplo, o $\mathrm{K}_{2} \mathrm{Cr}_{2} \mathrm{O}_{7}$ (bicromato de potássio) em meio ácido, sendo o resultado final desta oxidação o dióxido de carbono e água. É quantidade de $\mathrm{O}_{2}$ necessária para a oxidaçáo da matéria orgânica através de um agente químico.

Os valores de DQO da água de entrada no sistema, oriundo do poço 1 (P1) são expressos no fragmento extraído da Tabela 1 e são considerados baixos, o que demonstra a água ser de excelente qualidade.

Tabela 11 - Resultados obtidos para a Demanda Química de Oxigênio

\begin{tabular}{l|c|c|c|c|c|c|c}
\hline \multirow{3}{*}{ Parâmetros } & \multirow{2}{*}{ Unidades } & \multirow{2}{*}{$\begin{array}{c}\text { IN-001/06 } \\
\text { (SUDERHSA) }\end{array}$} & $\begin{array}{c}\mathbf{0 9 / 2 0 1 4} \\
\mathbf{P 1}\end{array}$ & $\begin{array}{c}\mathbf{0 9 / 2 0 1 4} \\
\mathbf{P 2}\end{array}$ & $\begin{array}{c}\mathbf{0 3 / 2 0 1 6} \\
\mathbf{P 1}\end{array}$ & $\mathbf{0 5 / 2 0 1 6}$ & $\mathbf{0 8 / 2 0 1 7}$ \\
& & & $\mathbf{P 1}$ & P1 \\
\hline \multirow{2}{*}{$\mathrm{DQO}$} & $\mathrm{mg} \cdot \mathrm{L}^{-1}$ & - & $<3,0$ & $<3,0$ & $<15,0$ & 17,0 & $<15,0$ \\
\hline
\end{tabular}

\section{II FERRO}

De acordo com Celligot (1999), o ferro é um dos mais importantes íons das rochas ígneas (42.200 $\left.\mathrm{mg} \cdot \mathrm{Kg}^{-1}\right)$. Ocorre principalmente em minerais máficos, como: piroxênios, anfibólios, biotitas, bem como magnetitas, piritas, dentre outros. $\mathrm{O}$ tipo mais comum de íon de ferro dissolvido na água subterrânea é o $\mathrm{Fe}^{2+}$. $\mathrm{O}$ $\mathrm{FeOH}^{+}$pode ocorrer com teores de $\mathrm{CO}_{2}$ baixos. Ferro trivalente pode ser dissolvido em soluçóes ácidas como $\mathrm{Fe}^{3+}, \mathrm{FeOH}^{2+}$ e $\mathrm{Fe}(\mathrm{OH})^{2+}$.

O ferro quando em quantidade acima do VMP pela legislação vigente é indesejável em águas de abastecimento público por conferir gosto, odor, manchar roupas e vasos sanitários, além de favorecer o desenvolvimento de ferrobactérias que podem obstruir canalizaçóes.

Conforme conferido no extrato da Tabela 1 para esse parâmetro, observa-se que os seus valores são mínimos se comparados com o VMP.

Tabela 11 - Resultados obtidos para o Ferro

\begin{tabular}{|c|c|c|c|c|c|c|c|}
\hline \multirow[b]{2}{*}{ Parâmetros } & \multirow[b]{2}{*}{ Unidades } & \multirow{2}{*}{$\begin{array}{c}\text { IN-001/06 } \\
\text { (SUDERHSA) }\end{array}$} & \multicolumn{5}{|c|}{ Resultados analíticos } \\
\hline & & & $\begin{array}{c}09 / 2014 \\
\text { P1 }\end{array}$ & $\begin{array}{c}09 / 2014 \\
\text { P2 }\end{array}$ & $\begin{array}{c}03 / 2016 \\
\text { P1 }\end{array}$ & $\begin{array}{c}05 / 2016 \\
\text { P1 }\end{array}$ & $\begin{array}{c}\text { 08/2017 } \\
\text { P1 }\end{array}$ \\
\hline Ferro & $\mathrm{mg} \cdot \mathrm{L}^{-1}$ & até 0,30 & $<0,01$ & $<0,01$ & NA & $<0,01$ & 0,10 \\
\hline
\end{tabular}

\section{12 FOSFATO TOTAL}

De acordo com Klein e Agne (2012), o fósforo é um elemento essencial à vida e tem uma distribuição muito irregular na natureza. Em muitas regiôes o fósforo $(\mathrm{P})$ é limitante a produção agrícola e adições periódicas de $\mathrm{P}$ se fazem necessárias para produção alimentos ou fibras. O P inorgânico que é adicionado ao solo como fertilizante tem baixa solubilidade em água e grande interação com partículas do solo. Sendo assim, a recomendação de adubação fosfatada é maior que a necessidade da cultura. O P também é considerado um grande poluente de cursos de água, especialmente as águas superficiais, já que pouco ocorre percolação deste elemento.

O P contido no material de origem encontra-se na forma mineral, sendo que as apatitas (fosfatos de cálcio) são os minerais primários mais comuns (FROSSARD et al., 1995), as formas e a distribuição do $\mathrm{P}$ no solo sob ambientes naturais estão intimamente ligado ao seu intemperismo. O P se movimenta pouco na 
maioria dos solos, sendo que geralmente permanece onde é colocado, seja por intemperismo dos minerais seja por adubação. Raramente é perdido por lixiviação, mesmo que este tenha maior mobilidade em solos arenosos. Quase todo o P se movimenta por difusão, sendo um processo lento e que depende da umidade. Devido a baixa mobilidade do P sua absorçáo pode ficar comprometida em solos compactados, devido ao fato da resistência mecânica do solo reduzir a habilidade das raízes na absorção, além de favorecer a sua adsorção específica (VAN RAIJ, 1991).

Santos et al. (2007) afirmam que o fósforo transportado através das águas subterrâneas, dos rios para os oceanos passa pelos estuários onde consideráveis processos ocorrem, alterando a disponibilidade biológica e o fluxo deste elemento para as áreas costeira e oceânica. O fósforo é assimilado pelo fitoplâncton, bactérias, e plantas bênticas, e é remineralizado por atividades heterotróficas dos animais e microrganismos.

A legislação brasileira não reconhece o $\mathrm{P}$ como contaminante de solo, reforçando a percepção do agricultor de que a adubação fosfatada deve obedecer a critérios produtivos e econômicos, não ambientais. Ainda a falta de definição da espécie de $\mathrm{P}$ e a metodologia padrão, conforme a resolução 357/05 do Conselho Nacional do Meio Ambiente (CONAMA) podem levar à possibilidade de se utilizar, como padrão, uma forma química que apresente riscos menores que os reais ou uma metodologia de baixa representatividade (GEBLER et al., 2012).

No Brasil a legislação do CONAMA, 2005 estabelece que o nível crítico de $\mathrm{P}$ total na água é de 0,020 - 0,025; 0,030 - 0,050 e 0,050 - 0,075 $\mathrm{mg} \mathrm{L}^{-1}$ nas Classes 1, 2 e 3 respectivamente. Para USEPA (1971) o nível crítico de $\mathrm{P}$ total não pode exceder $0,025 \mathrm{mg} \mathrm{L}^{-1}$. Em outros países e na maioria do meio científico utiliza-se o valor crítico de 0,020 $\mathrm{mg} \mathrm{L}^{-1}$ (CORRELL, 1998; HAYGARTH eJARVIS, 1999).

Em lagos na Inglaterra, onde o homem não desenvolveu atividades, a concentração de $\mathrm{P}$ é de 0,005 e $0,01 \mathrm{mg} \mathrm{L}^{-1}$ e em lagos na Itália de múltiplo uso a concentração é de 0,01 e $0,1 \mathrm{mg} \mathrm{L}^{-1}$. Assim, a concentração crítica estabelecida para efeitos de eutrofização foi de $0,02-0,035 \mathrm{mg} \mathrm{L}^{-1}$ (HECKRATH et al., 1995), mas observa-se que as concentraçóes encontradas ao longo do monitoramento, conforme extrato da Tabela 1 para esse parâmetro mostrado a seguir, são de baixas concentraçôes para os padróes brasileiros.

Tabela 11- Resultados obtidos para o Fosfato Total

\begin{tabular}{|c|c|c|c|c|c|c|c|}
\hline \multirow[b]{2}{*}{ Parâmetros } & \multirow[b]{2}{*}{ Unidades } & \multirow{2}{*}{$\begin{array}{c}\text { IN-001/06 } \\
\text { (SUDERHSA) }\end{array}$} & \multicolumn{5}{|c|}{ Resultados analíticos } \\
\hline & & & $\begin{array}{c}\text { 09/2014 } \\
\text { P1 }\end{array}$ & $\begin{array}{c}\text { 09/2014 } \\
\text { P2 }\end{array}$ & $\begin{array}{c}\text { 03/2016 } \\
\text { P1 }\end{array}$ & $\begin{array}{c}\text { 05/2016 } \\
\text { P1 }\end{array}$ & $\begin{array}{c}\text { 08/2017 } \\
\text { P1 }\end{array}$ \\
\hline Fosfato Total & $\mathrm{mg} \cdot \mathrm{L}^{-1}$ & - & $<0,05$ & $<0,05$ & NA & $<0,15$ & $<0,15$ \\
\hline
\end{tabular}

\section{I 3 FLUORETOS}

De acordo com Celligot (1999), o flúor ocorre mais abundantemente que o cloro em rochas ígneas: Fluorita $\left(\mathrm{CaF}_{2}\right)$ e apatita $\left(\mathrm{Ca}_{5}[\{\mathrm{~F}, \mathrm{Cl})]\left(\mathrm{PO}_{4}\right)_{3}\right]$ são constituintes de rochas ígneas e sedimentares. O fúor forma íons $\mathrm{F}$ em água, o qual pode formar complexos solúveis com Al, Be, Fe e B. Teores abaixo de 1,0 mg. $\mathrm{L}^{-1}$ são comuns em basaltos e arenitos. Teores altos de $\mathrm{F}^{-}$em águas subterrâneas são relacionados com deficiência em cálcio, o que não é o caso do presente estudo.

O flúor é determinado na forma de íon fluoreto. É importante na prevenção da cárie dental e pode ocorrer naturalmente. $\mathrm{O}$ excesso de flúor pode causar fluorose dentária, caracterizada pelo surgimento de manchas nos dentes da população, cuja coloração pode variar do branco ao marrom escuro, alteraçôes ósseas, inflamação no estômago e intestino.

A concentração de fluoreto é um parâmetro relevante para avaliação da qualidade nas águas de consumo, seja pela possibilidade de prevenção da cárie dentária, quando presente em níveis adequados, seja pelo potencial de provocar fluorose dentária, quando em níveis elevados. Estabelecer níveis de segurança para o fluoreto em águas de consumo é uma medida imprescindível de proteção à saúde humana.

De acordo com Frazáo et al. (2011), do ponto de vista da presença de fluoreto em águas de consumo humano, agregado ou de ocorrência natural, 1,7 mg. $\mathrm{L}^{-1} \mathrm{~F}$ foi fixado como VMP. Esse valor seria alterado em 2000 com a publicação da Portaria1.469, que definiu $1,5 \mathrm{mg} \cdot \mathrm{L}^{-1} \mathrm{~F}$ como VMP. Essa orientação foi mantida na Portaria $518^{1}$.

Observa-se na extração da Tabela 1 para esse parâmetro que os valores encontram-se em abaixo do VMP pela legislação vigente. 
Tabela 12 - Resultados obtidos para o Fosfato Total

\begin{tabular}{|c|c|c|c|c|c|c|c|}
\hline \multirow[b]{2}{*}{ Parâmetros } & \multirow[b]{2}{*}{ Unidades } & \multirow{2}{*}{$\begin{array}{c}\text { IN-001/06 } \\
\text { (SUDERHSA) }\end{array}$} & \multicolumn{5}{|c|}{ Resultados analíticos } \\
\hline & & & $\begin{array}{c}\text { 09/2014 } \\
\text { P1 }\end{array}$ & $\begin{array}{c}\text { 09/2014 } \\
\text { P2 }\end{array}$ & $\begin{array}{c}\text { 03/2016 } \\
\text { P1 }\end{array}$ & $\begin{array}{c}\text { 05/2016 } \\
\text { P1 }\end{array}$ & $\begin{array}{c}\text { 08/2017 } \\
\text { P1 }\end{array}$ \\
\hline Fluoretos & $\mathrm{mg} \cdot \mathrm{L}^{-1}$ & Até 1,5 & $<0,10$ & 0,15 & $<0,10$ & 0,10 & $<0,10$ \\
\hline
\end{tabular}

\section{14 HIDRÓXIDOS}

Os valores de hidróxidos na água de entrada do processo agroindustrial se mantem constante ao longo dos monitoramentos realizados e não existe VMP pela legislação vigente no país, conforme pode ser observado no recorte do extrato da Tabela 1 para esse parâmetro.

Tabela 13 - Resultados obtidos para o Fosfato Total

\begin{tabular}{|c|c|c|c|c|c|c|c|}
\hline \multirow[b]{2}{*}{ Parâmetros } & \multirow[b]{2}{*}{ Unidades } & \multirow{2}{*}{$\begin{array}{c}\text { IN-001/06 } \\
\text { (SUDERHSA) }\end{array}$} & \multicolumn{5}{|c|}{ Resultados analíticos } \\
\hline & & & $\begin{array}{c}\text { 09/2014 } \\
\text { P1 }\end{array}$ & $\begin{array}{c}\text { 09/2014 } \\
\text { P2 }\end{array}$ & $\begin{array}{c}\text { 03/2016 } \\
\text { P1 }\end{array}$ & $\begin{array}{c}\text { 05/2016 } \\
\text { P1 }\end{array}$ & $\begin{array}{c}\text { 08/2017 } \\
\text { P1 }\end{array}$ \\
\hline Hidróxidos & $\mathrm{mg} . \mathrm{L}^{-1}$ & - & NA & NA & $<3,0$ & $<3,0$ & $<3,0$ \\
\hline
\end{tabular}

\section{I5 MAGNÉSIO}

De acordo com Celligot (1999), as principais ocorrências desse elemento químico estão nas olivinas $\left(\mathrm{MgSiO}_{4}\right.$ - forsterita), granadas, piroxênios, dentre outras. $\mathrm{O}$ íon magnésio tem raio iônico menor e densidade de carga maior que o sódio e o potássio e tende a formar revestimento de 6 moléculas de água $-\mathrm{Mg}\left(\mathrm{H}_{2} \mathrm{O}\right)_{6}{ }_{6}^{2+}$.

Tem grande solubilidade, mas é encontrado em menores quantidades nas águas doces, mais provavelmente pela baixa abundância geoquímica do magnésio (17.600 mg. $\mathrm{Kg}^{-1}$ nas rochas ígneas).

Conforme extrato da Tabela 1 para esse parâmetro, a variação desse elemento nas águas extraídas do poço 1 (P1), apresentam flutuaçóes que variam de 5,63 a 15,82 mg. $\mathrm{L}^{-1}$ e não existe VMP pelas legislaçóes para esse parâmetro.

Tabela 14 - Resultados obtidos para o Magnésio

\begin{tabular}{|c|c|c|c|c|c|c|c|}
\hline \multirow[b]{2}{*}{ Parâmetros } & \multirow[b]{2}{*}{ Unidades } & \multirow{2}{*}{$\begin{array}{c}\text { IN-001/06 } \\
\text { (SUDERHSA) }\end{array}$} & \multicolumn{5}{|c|}{ Resultados analíticos } \\
\hline & & & $\begin{array}{c}09 / 2014 \\
\text { P1 }\end{array}$ & $\begin{array}{c}\text { 09/2014 } \\
\text { P2 }\end{array}$ & $\begin{array}{c}\text { 03/2016 } \\
\text { P1 }\end{array}$ & $\begin{array}{c}\text { 05/2016 } \\
\text { P1 }\end{array}$ & $\begin{array}{c}\text { 08/2017 } \\
\text { P1 }\end{array}$ \\
\hline Magnésio & mg. $L^{-1}$ & & 5,63 & 12,25 & NA & 9,74 & 15,82 \\
\hline
\end{tabular}

\section{16 MANGANÊS}

De acordo com Celligot (1999), o manganês está presente em substituiçóes em biotita e hornblenda, principalmente. É o elemento principal da rodcrosita.

Em considerações normais esse elemento é detectável em pequenas quantidades na água subterrânea.

Concentraçôes acima de $1,0 \mathrm{mg} \cdot \mathrm{L}^{-1}$ sãoraras, mas valores como $0,05 \mathrm{mg} \cdot \mathrm{L}^{-1}$ terão efeito adverso na potabilidade da água.

Conforme conferido no extrato da Tabela 1 para esse parâmetro, observa-se que os seus valores são mínimos $\left(<0,005\right.$ para todas as análises) se comparados com o adverso de $0,05 \mathrm{mg} \cdot \mathrm{L}^{-1}$ ou VMP que é de $0,1 \mathrm{mg} \cdot \mathrm{L}^{-1}$.

Tabela 15 - Resultados obtidos para o Manganês

\begin{tabular}{l|c|c|c|c|c|c|c}
\hline \multirow{3}{*}{ Parâmetros } & \multirow{2}{*}{ Unidades } & \multirow{2}{*}{$\begin{array}{c}\text { IN-001/06 } \\
\text { (SUDERHSA) }\end{array}$} & \multicolumn{6}{|c}{ Resultados analíticos } \\
\cline { 4 - 8 } & & & P1 & P2 & P1 & P1 & P1 \\
\hline Manganês & mg.L $\mathrm{L}^{-1}$ & até 0,100 & $<0,005$ & $<0,005$ & NA & $<0,005$ & $<0,005$ \\
\hline
\end{tabular}




\section{17 Nitrogênio e Nitrato (NO3-)}

O aumento da contaminaçáo das águas por compostos nitrogenados vem merecendo atençáo especial, uma vez que está se tornando um problema mundial, devido a sua ampla e diversificada procedência (ROVIRA e CANOVES, 1988; MATO, 1996; MACLEAF e SCHOEDER, 1995; BOUCHARD et al., 1992)

De acordo com Celligot (1999), o elemento nitrogênio se apresenta na natureza de diferentes formas $\left(\mathrm{N}_{\text {org }}\right.$ $\mathrm{NH}_{3}-\mathrm{NO}_{2}-\mathrm{NO}_{3}$ ) sendo formas essas bioquimicamente interconversíveis e componentes do ciclo do nitrogênio.

No processo de oxidação da matéria orgânica, os microrganismos transformam $\mathrm{NO}_{2}{ }^{-} \mathrm{em} \mathrm{NO}_{3}$, cujoteor está relacionado às condiçóes de oxigenaçáo da água. Concentraçóes elevadas de $\mathrm{N}_{\mathrm{org}} \mathrm{e} \mathrm{NH}_{4}^{+}$indicam poluição recente; altas concentraçôes de $\mathrm{NO}_{3}^{-}$indicam poluiçấo antiga.

Praticamente todos os nitratos são solúveis em água. Alguns produzem sais básicos quando tratados em água, os quais são solúveis em ácido nítrico diluído.

O nitrogênio é um composto de grande importância para o crescimento das plantas, porém, em determinadas condições, é convertido em nitrato, o qual pode ser absorvido pelas plantas ou lixiviado para a água subterrânea após a ocorrência de chuva pesada ou irrigação intensa (RICO-GARCÍA et al., 2009). A mobilidade do nitrato em solo está relacionada a fatores como a textura e umidade do solo e à sua disponibilidade, sendo assim, o nitrato se torna a principal forma de nitrogênio associada à contaminaçáo dos reservatórios de água subterrânea devido a atividades antropogênicas (SILVA et al., 2015). O VMP para este contaminante é de apenas $10,0 \mathrm{mg} \mathrm{L}^{-1}$ (USEPA, 1987).

$\mathrm{O} \mathrm{NO}_{3}$ - também é considerado padrão de potabilidade, sendo necessário seu controle em águas destinadas ao consumo. Tanto a Portaria do Ministério da Saúde no 2.914 de 2011 quanto a Resolução CONAMA no 396 de 2008 delimitam a concentraçáo deste parâmetro em 10,0 mg de $\mathrm{N} \mathrm{L}^{-1}$, expresso como N.

Os valores encontrados de $\mathrm{NO}_{3}^{-}$nos monitoramentos realizados indicam que estáo abaixo do estabelecido pela legislação em vigor.

Tabela 16 - Resultados obtidos para o Nitrato

\begin{tabular}{|c|c|c|c|c|c|c|c|}
\hline \multirow[b]{2}{*}{ Parâmetros } & \multirow[b]{2}{*}{ Unidades } & \multirow{2}{*}{$\begin{array}{c}\text { IN-001/06 } \\
\text { (SUDERHSA) }\end{array}$} & \multicolumn{5}{|c|}{ Resultados analíticos } \\
\hline & & & $\begin{array}{c}\text { 09/2014 } \\
\text { P1 }\end{array}$ & $\begin{array}{c}\text { 09/2014 } \\
\text { P2 }\end{array}$ & $\begin{array}{c}\text { 03/2016 } \\
\text { P1 }\end{array}$ & $\begin{array}{c}\text { 05/2016 } \\
\text { P1 }\end{array}$ & $\begin{array}{c}\text { 08/2017 } \\
\text { P1 }\end{array}$ \\
\hline Nitrogênio e Nitrato & $\mathrm{mg} \cdot \mathrm{L}^{-1}$ & Até 10,0 & 5,1 & 6,2 & 6,6 & 2,3 & 2,4 \\
\hline
\end{tabular}

\section{8 NiTROgÊNIO e NitRITO (NO2-)}

Todos os nitritos são solúveis em água, com exceção do nitrito de prata que é pouco solúvel. A amostra utilizada para reaçóes para o íon nitrito foi do sal nitrato de sódio.

O nitrito, quando presente na água de consumo humano, tem um efeito mais rápido e pronunciado do que o nitrato. Se o nitrito for ingerido diretamente, pode ocasionar metemoglobinemia independente da faixa etária do consumidor (BATALHA e PARLATORE, 1993).

Os valores encontrados de $\mathrm{NO}_{3}^{-}$nos monitoramentos realizados indicam que estáo abaixo do estabelecido pela legislação em vigor.

Tabela 17 - Resultados obtidos para o Nitrito

\begin{tabular}{c|c|c|c|c|c|c|c}
\hline \multirow{2}{*}{ Parâmetros } & \multirow{2}{*}{ Unidades } & \multirow{2}{*}{ IN-001/06 } & \multicolumn{5}{|c}{ Resultados analíticos } \\
\cline { 4 - 8 } & & (SUDERHSA) & $\mathbf{0 9 / 2 0 1 4}$ & $\mathbf{0 9 / 2 0 1 4}$ & $\mathbf{0 3 / 2 0 1 6}$ & $\mathbf{0 5 / 2 0 1 6}$ & $\mathbf{0 8 / 2 0 1 7}$ \\
& & & P1 & P2 & P1 & P1 & P1 \\
\hline Nitrogênio e Nitrito & mg.L-1 & Até 1,0 & $<0,01$ & $<0,01$ & $<0,01$ & 0,02 & $<0,01$ \\
\hline
\end{tabular}

\subsection{PotásSIO}

De acordo com Celligot (1999), com $25.700 \mathrm{mg} \cdot \mathrm{Kg}^{-1} \mathrm{em}$ rochas ígneas, ocorre na forma de vários minerais, como microclima e ortoclásio ( $\mathrm{KAlSi}_{3} \mathrm{O}_{8}$ ), muscovita e biotita, entre outros. Os íons sáo liberados pelo intemperismo. Entretanto, após migração mais ou menos prolongada, eles tendem a fixar-se, adsorvidos em minerais de argila, entre os espaços da ilita, formando minerais secundários. Tem, nessa forma, pouca mobilidade geoquímica nas águas doces e é raramente encontrado em concentraçóes iguais ou maiores que o sódio.

Conforme extrato da Tabela 1 para esse parâmetro, a variação desse elemento na águas extraídas do poço 1 (P1), apresentam flutuações que variam de $<1,0 \mathrm{a} 1,8 \mathrm{mg} \cdot \mathrm{L}^{-1} \mathrm{e}$ não existe VMP pelas legislações para esse parâmetro. 
Tabela 17 - Resultados obtidos para o Potássio

\begin{tabular}{|c|c|c|c|c|c|c|c|}
\hline \multirow[b]{2}{*}{ Parâmetros } & \multirow[b]{2}{*}{ Unidades } & \multirow{2}{*}{$\begin{array}{c}\text { IN-001/06 } \\
\text { (SUDERHSA) }\end{array}$} & \multicolumn{5}{|c|}{ Resultados analíticos } \\
\hline & & & $\begin{array}{c}\text { 09/2014 } \\
\text { P1 }\end{array}$ & $\begin{array}{c}\text { 09/2014 } \\
\text { P2 }\end{array}$ & $\begin{array}{c}\text { 03/2016 } \\
\text { P1 }\end{array}$ & $\begin{array}{c}\text { 05/2016 } \\
\text { P1 }\end{array}$ & $\begin{array}{c}\text { 08/2017 } \\
\text { P1 }\end{array}$ \\
\hline Potássio & mg.L-1 & - & 1,8 & $<1,0$ & NA & 1,2 & $<1,0$ \\
\hline
\end{tabular}

\subsection{SíLICA DisSOLVIDA}

De acordo com Celligot (1999), a sílica é o segundo elemento mais abundante na crosta terrestre. O volume de sílica ocorrente nas águas subterrâneas vem do intemperismo de minerais silicatados, enquanto que a sílica cristalina (quartzo) é quase insolúvel.

Concentrações muito altas de sílica são encontradas em águas com pH acima de 9 e são muito raras.

Os valores apresentados ao longo do monitoramento, conforme extrato da Tabela 1 extraído para esse parâmetro, não apresentam risco algum ao processo agroindustrial e a legislação vigente não estabelece um VMP.

Tabela 18 - Resultados obtidos para a Sílica Dissolvida

\begin{tabular}{|c|c|c|c|c|c|c|c|}
\hline \multirow[b]{2}{*}{ Parâmetros } & \multirow[b]{2}{*}{ Unidades } & \multirow{2}{*}{$\begin{array}{c}\text { IN-001/06 } \\
\text { (SUDERHSA) }\end{array}$} & \multicolumn{5}{|c|}{ Resultados analíticos } \\
\hline & & & $\begin{array}{c}\text { 09/2014 } \\
\text { P1 }\end{array}$ & $\begin{array}{c}\text { 09/2014 } \\
\text { P2 }\end{array}$ & $\begin{array}{c}\text { 03/2016 } \\
\text { P1 }\end{array}$ & $\begin{array}{c}05 / 2016 \\
\text { P1 }\end{array}$ & $\begin{array}{c}\text { 08/2017 } \\
\text { P1 }\end{array}$ \\
\hline Sílica dissolvida & $\mathrm{mg} \cdot \mathrm{L}^{-1}$ & - & 47,5 & 26,0 & 50,7 & 50,3 & 16,7 \\
\hline
\end{tabular}

\subsection{SódiO}

De acordo com Celligot (1999), o sódio é um constituinte maior das rochas ígneas (28.000 mg. $\left.\mathrm{kg}^{-1}\right)$. Ocorre em plagioclásio, principalmente albita $\left(\mathrm{NaAlSi}_{3} \mathrm{O}_{8}\right)$ e é liberado durante o intemperismo destes silicatos (MATTHESS, 1982).

O Sódio é geralmente presente nas águas doces como íons $\mathrm{Na}^{+}$, em soluçōes concentradas ocorrem $\mathrm{NaCO}_{3}^{-}, \mathrm{NaHCO}_{3} \mathrm{e} \mathrm{NaSO}_{4}^{-}$. As mais altas concentraçóes ocorrem em associação com íons $\mathrm{Cl}^{-}$.

Conforme extrato da Tabela 1 para esse parâmetro, a variação desse elemento na águas extraídas do poço 1 (P1), apresenta flutuaçóes que variam de 12,0a 14,8 mg. $\mathrm{L}^{-1}$ e bem abaixo do VMP pelas legislaçóes para esse parâmetro que é de $200 \mathrm{mg} . \mathrm{L}^{-1}$.

$\mathrm{O}$ monitoramento desse parâmetro é fundamental pelo fato do processo agroindustrial em estudo ter a entrada de cloreto de sódio na fase 1 de dessalga do material onde o mesmo tem que ser monitorado.

Tabela 19 - Resultados obtidos para o Sódio

\begin{tabular}{|c|c|c|c|c|c|c|c|}
\hline \multirow[b]{2}{*}{ Parâmetros } & \multirow[b]{2}{*}{ Unidades } & \multirow[b]{2}{*}{$\begin{array}{c}\text { IN-001/06 } \\
\text { (SUDERHSA) }\end{array}$} & \multicolumn{5}{|c|}{ Resultados analíticos } \\
\hline & & & $\begin{array}{c}09 / 2014 \\
\text { P1 }\end{array}$ & $\begin{array}{c}\text { 09/2014 } \\
\text { P2 }\end{array}$ & $\begin{array}{c}\text { 03/2016 } \\
\text { P1 }\end{array}$ & $\begin{array}{c}\text { 05/2016 } \\
\text { P1 }\end{array}$ & $\begin{array}{c}\text { 08/2017 } \\
\text { P1 }\end{array}$ \\
\hline Sódio & $\operatorname{mg} . \mathrm{L}^{-1}$ & até 200 & 14,8 & 54,2 & NA & 12,0 & 13,5 \\
\hline
\end{tabular}

\subsection{SUlFATO}

De acordo com Celligot (1999), o enxofre ocorre principalmente em gases magmáticos. A maior parte do elemento nas rochas ocorre em minerais como o gipso $\left(\mathrm{CaSO}_{4} \cdot \mathrm{H}_{2} \mathrm{O}\right)$ e anidrita $\left(\mathrm{CaSO}_{4}\right)$. Consideráveis quantidades de sulfato são adicionadas ao ciclo hidrológico com as precipitaçóes da atmosfera. Vêm do 'spray' marinho, da poeira dos continentes e da oxidaçáo de $\mathrm{H}_{2} \mathrm{~S}$, bem como das substancias orgânicas do solo.

Nas águas subterrâneas circulantes em rochas ígneas, a concentração de sulfato é baixa $\left(<30 \mathrm{mg} . \mathrm{L}^{-1}\right)$.

A quantidade de Sulfato encontrado no monitoramento da água de entrada no sistema agroindustrial (P1) tem se mostrado constante e muito abaixo do VMP pela legislação vigente, conforme extrato da Tabela 1 para esse parâmetro. 
Tabela 20 - Resultados obtidos para o Sulfato

\begin{tabular}{|c|c|c|c|c|c|c|c|}
\hline \multirow[b]{2}{*}{ Parâmetros } & \multirow[b]{2}{*}{ Unidades } & \multirow{2}{*}{$\begin{array}{c}\text { IN-001/06 } \\
\text { (SUDERHSA) }\end{array}$} & \multicolumn{5}{|c|}{ Resultados analíticos } \\
\hline & & & $\begin{array}{c}\text { 09/2014 } \\
\text { P1 }\end{array}$ & $\begin{array}{c}\text { 09/2014 } \\
\text { P2 }\end{array}$ & $\begin{array}{c}03 / 2016 \\
\text { P1 }\end{array}$ & $\begin{array}{c}05 / 2016 \\
\text { P1 }\end{array}$ & $\begin{array}{c}\text { 08/2017 } \\
\text { P1 }\end{array}$ \\
\hline Sulfato & $\mathrm{mg} \cdot \mathrm{L}^{-1}$ & Até 250 & $<2,0$ & $<2,0$ & $<2,0$ & $<2,0$ & $<2,0$ \\
\hline
\end{tabular}

\section{CONCLUSÃO}

Com base nos resultados das análises, pode-se concluir que para os parâmetros químicos, todos os resultados encontram-se dentro dos limites máximos para consumo humano, referendado como de ótima qualidade.

A análise destes parâmetros são essenciais não só para o controle da qualidade da água, mas também podem ser usados como indicadores ambientais. Dessa forma, novas análises periódicas devem ser realizadas a fim de se manter o controle ambiental e de promover a saúde dos indivíduos que trabalham ou habitam regióes próximas as áreas de curtumes.

Outro aspecto importante de ser considerado e pesquisado é a análise da água proveniente de curtumes de outras regióes, que poderiam ser comparadas no espaço e no tempo a fim de se obter informaçóes dos fatores ou causas que proporcionam o desequilíbrio químico da amostra, o que por sua vez conduziria a açóes que inibam tais causas.

Por sua vez, o estudo dos parâmetros físicos e biológicos da água de entrada em curtume também constitui um excelente campo de investigação, pois permitiria uma análise mais completa de todos os parâmetros que influenciam o meio ambiente e a saúde humana quando se considera a água de entrada de um sistema agroindustrial de curtume.

\section{REFERÊNCIAS}

AGUAS GUARIROBAS. Qualidade da água. Disponível no endereço eletrônico: http://www.aguasguariroba.com.br/ qualidade-agua/ e acessado em 31.out.2017.

AWWA - AMERICAN WATER WORKS ASSOCIATION. Advances in taste and odor treatment and control. Denver, AWWARF, 385p. 1995.

AWWA - AMERICAN WATER WORKS ASSOCIATION.- [Standard Methods] 1998, 0-87553-235-7, American Water Works Association, Water Environment. 1998

ANVISA - Agência Nacional de Vigilância Sanitária. Resoluçáo - CNNPA no 12, de 1978. D.O.U. de 24/07/1978. Disponível no endereço eletrônico: http://www.anvisa.gov.br/anvisalegis/resol/12_78.pdf e acessado em 31.out.2017.

BATALHA, B.H.L.; PARLATORE, A.C. Controle da qualidade da água para consumo humano: bases conceituais e operacionais. São Paulo, CETESB, 1993.

BOUCHARD, D.C.; WILLIANS, M.K.; SURAMPALLI, R.Y. Nitrate contamination of ground water: sources and potencial health effects. J. Am. Water Works Ass., 84: 85-90,1992.

BRASIL. Conselho Nacional do Meio Ambiente. Resoluçáo CONAMA no 396, de 3 de abril de 2008. Diário Oficial da União. 7 abr. 2008.

BRASIL. Ministério da Saúde. Portaria do Ministério da Saúde no 2.914, de 12 de dezembro de 2011. Diário Oficial da Uniáo, 14 dez. 2011. 
BRASIL. Ministério do Planejamento: Instituto Brasileiro de Geografia e Estatística - IBGE. Cidade de Buritis, Estado de Rondônia. 2010. Disponível no endereço eletrônico: http://www.ibge.gov.br/cidadesat/link.php?uf=ro> acesso em: 01.nov.2017.

CELLIGOT, A. Considerações sobre análises químicas de águas subterrâneas. Geografia, Londrina, V. 8, n. 1, p. 91-97, jan.! jun. 1999.

CORRELL, D.L. The role of phosphorus in the eutrophication of receiving waters: A review. Journal Environmental Quality. v. 27, p. 261-266, 1998.

FRAZÃO, P.; PERES, M.A.; CURY, J.A. Qualidade da água para consumo humano e concentração de fluoreto. Rev Saúde Pública, 2011. Disponível no endereço eletrônico: http://www.scielo.br/pdf/rsp/2011 nahead/2584.pdf e acessado em 01.nov.2017

FREEZE, R.A.; CHERRY, J.A. Groundwater. N Jersey, Prentice-Hall inc., 1979, 604 p.

FROSSARD, E.; BROSSARD, M.; HEDLEY, M.J.; METHERELL, A. Reactions controlling the cycling of P in soils. In: TIESSEN, H (Ed). Phosphorus in the global environmental: transfers, cycles and management. 1. ed. Chichester, U.K: Wiley, p. 107-137, 1995.

GEBLER, L.; LOUZADAS, J.A.S.; BERTOL, I.; RAMOS, R.R.; MIQUELLUTI, D.J.; SCHRAMMELS, B.M. Adaptação metodológica no cálculo de cargas contaminantes de P em bacias hidrográficas gaúchas. Revista Brasileira de Engenharia Agrícola e Ambiental. v.16, n.7, p.769-776, 2012

HAYGARTH, P.M.; JARVIS, S.C. Transfer of phosphorus from agricultural soils. Advance Agronomic. v. 66, p. 196249, 1999.

HECLRATH, G.; BROOKES, P.C.; POULTON, P.R.; GOULDING, K.W.T 1995. Phosphorusleaching from soils containing different phosphorus concentrations in the Broadbalk experiment. J. Environ. Qual., 24:904-910.

KLEIN, C.; AGNE, S.A.A. FÓSFORO: DE NUTRIENTE À POLUENTE! Rev. Elet. em Gestáo, Educaçáo e Tecnologia Ambiental v(8), no 8, p. 1713-1721, SET-DEZ, 2012. Disponível no endereço eletrônico: http://cascavel.ufsm.br/ revistas/ojs-2.2.2/index.php/reget 1713 e acessado em 01.nov.2017.

LEE, J.D. Química inorgânica não táo concisa. Tradução da $5^{a}$ ed. Inglesa/Henrique E. Toma, Koiti Araki, Reginaldo C. Rocha. São Paulo; Bucher, 1999.

MACLEAF, P.R.; SCHOEDER, E.D. Denitrification using a membrane-immobolized biofilm. J. W. Works Ass, v.87, p.77-86, 1995.

MAGALHÃES, A.B.S. Gosto e odor na água para consumo humano - um problema de saúde pública. 2016. Disponível no endereço eletrônico: https://www.diariodecaratinga.com.br/?p=18804 e acessado em 31.out.2017.

MANUAL TÉCNICOS PARA COLETA DE AMOSTRAS DE ÁGUA, Ministério Público de Santa Catarina. Disponível no endereço eletrônico file://C:/Users/admin/Downloads/livro-manual-tecnico-para-coleta-de-amostras-de-agua-mp-sc.pdf e acessado em 29.out.2017.

MATO, A.P. Determinação de nitratos, nitritos e prováveis fontes de contaminação em águas de poços e sua influência na metemoglobinemia infantil. São Paulo, 1996. [Dissertação de Mestrado - Curso de Pós-Graduação em Saneamento Ambiental, Universidade Mackenzie].

MATTHESS, G. The Properties of Groundwater. New York, John Willey \& Sons, 1982. 406 p.

METCALF \& EDDY, INC. Wastewater Engineering - Treatment, disposal and reuse, third edition. McGraw-Hill book Co, 1991. 
MINISTÉRIO DA SAÚDE. Portaria no 56/Bsb, de 14 de março de 1977. Aprova normas e o padrão de potabilidade da água a serem observados em todo o território nacional. Diario Oficial Uniao. 22 mar. 1977.

RICO-GARCÍA, E.;CASANOVA-VILLAREAL, V.E.; MERCADO-LUNAG, A.; SOTO-ZARAZUA, M.Nitrate content on summer lettuce production using fish culture water. Trends in Agricultural Economics, v. 2, n. 1, 2009.

ROCHA, J.C.; ROSA, A.H.; CARDOSO, A.A. Introdução à Química Ambiental. 2. ed. Porto Alegre: Bookman, 2009. 154 p.

ROSA, C.C.B.; ALMEIDA, F.T.; SANTOS JUNIOR, E.L.; ALVES, M.G.; MARTINS, M.L.L. QUALIDADE

MICROBIOLÓGICA DE ÁGUA DE POÇOS PROVENIENTES DE ÁREAS URBANAS E RURAIS DE CAMPOS

DOS GOYTACAZES (RJ). XIII Congresso Brasileiro de Águas Subterrâneas (S/D). Disponível no endereço eletrônico: file:///C:/Users/admin/Downloads/23603-85569-1-PB.pdf e acessado em 01.nov.2017.

ROSA FILHO, E.F.; HINDI, E.C.; MANTOVANI, L.E.; BITTENCOURT, A.V.L. As Águas subterrâneas do Estado do Paraná. Curitiba: Maxi Gráfica, 2010.

ROSA FILHO, E.F.; HINDI, E.C.; MANTOVANI, L.E.; BITTENCOURT, A.V.L.. Aquíferos do Estado do Paraná. Curitiba: Maxi Gráfica, 2011.

ROVIRA, R.F.; CANOVES, A.F. Nitratos, aspectos bromatológicos, toxicológicos e analíticos. Alimentaria, Madrid, 24: 15-21, 1988.

SABESP - Companhia de Saneamento Básico do Estado de Sáo Paulo. Norma Técnica Interna SABESP NTS 013 SÓLIDOS Método de Ensaio. São Paulo Junho - 1999 Revisão 1. 12 p.

SANTOS, M.L.S.; MUNIZ. K.; FEITOSA, F.AN.; BARROS NETO, B. Estudo das diferentes formas de fósforo nas águas da plataforma continental do Amazonas.Quím. Nova vol.30 no.3 São Paulo Mai/Jun. 2007

SCHRYVER, P.D; CRAB, R.; DEFOIRDT, N.; BOON, W. The basics of bio-flocs technology: The added value for aquaculture. Aquaculture, v. 277, p. 125-137, 2008.

SILVA, L.P.; MIRANDA, J.H.; OLIVEIRA, L.A.; JOSE, J.V. Effect of companion ion on nitrate displacement through transport parameters analysis. Eng Agr., v. 35, n. 1, 2015.

TABELA PERÍODICA ONLINE. Metais alcalinos terrosos. 2008. Disponível em: < http://www.tabela.oxigenio.com/ metais_alcalinos_terrosos/>. Acessado em 01.nov.2017.

TUCCI, C.E.M.; CABRAL, J.J.S.P. Prospecção tecnológica, recursos hídricos: qualidade da água. Brasília, DF: CGEE, 2003. Disponível em: http://www.cgee.org.br/arquivos/a2b_agua_sub.pdf. Acesso em: 01.nov.2017.

USEPA - United States Environmental Protection Agency. Methods of chemical analysis for water and water. Cincinnati: USEPA, 1971.

VAN RAIJ, B. Fertilidade do solo e adubação. Piracicaba: Ceres; Potafos, 1991.

VENDEMIATTO, M. A.; ENZWEILER, J.; PEREIRA, S.Y.; BATISTA, J.J.F. Análise de Ânions em Água por Cromatografia de Íons - Controle de Qualidade Instituto de Geociências. (s/d). UNICAMP, Campinas-SP. Disponível no endereço eletrônico: http://www.sbgq.org.br/phocadownload/XI/119.pdf Acessado em 31.out2017. 